\title{
日本醫科大學雜誌
}

第 7 卷 第 9 號 昭和 11 年 9 月 15 日發行

\section{Lawn Tennis Studied from the Medical Point of View}

\author{
(Report No. I) \\ By \\ R. Sakurai. \\ From the Orthopaedic Clinic of the Nippon ,Medical College, Tokyo. \\ (Director: : Prof. Dr. K. Saito.) \\ (The abstract form Nihon Seikeigekarakki Z. Band \\ 9. No. 5, No. 6 and Band 10 No. 1 1935).
}

\section{Introduction.}

Recently, various kind of athletic sports are being medically studied ove after a other with the advance of what is called "Sportmedicine". But little has been dove in the field of tennis. Although we have the reports of Dr. Rosenberg, Hohmann, Preiser, and Lorentz, all of them are partial and almost limited to those on the elbow joint, only. Similar reports have been made in Japan, but, as far as I can see, that of tennis from the medical point of view has never been made hitherto.

\section{Method of study.}

\section{Material for examination.}

The examination was made on the 54 leading male tennis players in Japan every time in their quiet state. In order to make a comparison between tennis players and other athletes, the examination was also made in the same state on the following:

64 student-fencers. (Kendo).

18 javelin-throwers.

17 baseball players. (pitchers only)

6 swimmers. (breast-stroke)

22 non-athlete males.

40 non-athlete females.

Total

221 


\section{Examination in Clinical Method.}

A. Diagnosis by questioning.

To make the result of this examination as perfect as possible, examination was made on the following points :

1. Anamnesis.

2. When did he begin playing tennis ?

3. How long?

4. What kind of 'grip' does he use? and is he right-handed or left-handed? (the serviceable arm)

a. The 'grip' used at present.

b. The 'grip' used for the longest period up to the present.

5. Wounds caused by playing tennis.

a. What kind of the wound and the date?

b. Wounded part.

c. To what extent?

d. Cause

6. Other diseases caused by playing tennis.

a. What kind of disease and the date attacked?

b. Condition.

c. Cause.

7. Experiences in other sports besides temnis.

a. Kind of the sport.

b. The date started and the duration.

c. Extent of exercise.

8. Extent of exercise in temnis.

9. Subjective symptom at the elbow joint.

a. Part and condition.

b. Cause.

c. The date attacked, frequency, and the duration.

The examination on the same points were also made on other athletes above mentioned.

B. Measurements of the upper limbs.

1. Measurements of the whole length of the upper limbs.

Measurements were taken on the length from the upper surface of the greater tubercle of the humerus, right and left respectively.

2. Measurements of the largest circumference of the forearm. 
Every time measurements were taken on the circumference of both arm at its largest part, in order to make a comparison between them.

3. Measurements of the carrying angle of the elbow joint.

Measurement of the carrying angle were taken on both arms respectively.

4. Measurements of the grasping power.

Measurements of the grasping power were taken by Collin's dynamometer, and the acutual number was based on the average taken twice on both arms respectively.

C. Measurements of height and weight.

As the material for physical examination, the height and weight were measured on all the examined.

\section{The examination by the $\mathbf{X}$-ray.}

A. The elbow joint.

In order to make a coxparison between the right and left arms, every time veutrodorsal and lateral photographs of the elbow joint were takes of all the examined.

1. Ventro-dorsal Photograph.

The upper arm was kept on a level with the shoulder with the elbow joint extended and the forearm in the supine position, while the elbow joint was fixed by keeping the lateral epicondyle and the medial epicondyle on a level. The focus of the $\mathbf{x}$-ray was cast perpendicularly on the fossa of the elbow joint with the $80 \mathrm{c} . \mathrm{m}$. forcal-length.

2. Lateral photograph.

In this case the upper arm was also kept on a level with the shoulder joint. Then, the medial aud lateral epicondyles were fixed on a vertical line, with the elbow joint bent at an angle of $60^{\circ}$. The photographs were taken with the $80 \mathrm{~cm}$. focal-length of the right and left arms for the comparison photographing, - one keeping the ulna so as to face the plate and the styloid processes of the ulna and the radius on a perpendicular line, and the other keeping the forearm in the prone position, fixing the styloid processes of the ulna and the radius on a level, for both arms respectively.

As for the focus of the $x$-ray, it was cast perpendicularly on the lateral epicondyle. If unusual images were noticed in the photographs, every possible cubic photograph was taken for the iuspection of the position, shape, etc.

B. The breast.

In all cases, $x$-ray photographing of the breast was made with $2 \mathrm{~m}$. focal-length in the state of standing. Each was taken at the moment the examined was made to hold breath at the deepest breathing, and the backside tip of the fifth spinous process of 
the breast backbone as its centre ventro-dorsal photographing was made.

However, it will not be reported here.

\section{Observations.}

Thus, observations were made on the physical structure, on the changes on the upper limbs perceived by the clinical examination, and on the changes on the elbow joivt perceived by the $x$-ray, and comparison was made between tennis players and other people mentioned above. The result will be stated briefly.

As the result of observations, it is proved that most tennis players have comparatively delicate physiques. In other words, their weights do not keep pace with their heights, as comparel with other athletes. The fact that all these are our first-class players shows that tennis is the possible sport for the one with comparatively delicate physique.

The average grasping power is 37,2 in the serviceable arm and 29,0 in the other, the difference of which amounts to 8,2 . Javelin-throwers have the strongest grasping power in both arms. While the grasping power of tennis players is about the same as other athletes, such as fencer, swimmers, etc., the difference between right and left arms is greatest among them.

As the result of the clinical examination, it is found that the upper arms of tennis players, especially those of 'Continental grip' users, develop abnormally, in comparison with other athletes and non-athletes. The movements of the elbow joint of teunis player are not so limited as compared with other athletes, especially fencers, javeliu-throwers, and baseball players. The most limited movement of the elbow joint is the supination of the for aarm, then comes the extension, and the least limited is the flexion movement. And those limited movements are most remarkable in the case of 'Continental grip' users. 'This limit of movements of the elbow joint is caused not only by the abnormal shape or development of the bones forming the elbow joint but also by the abnormal condition of the soft tissues. The 'Continental grip' users, whose elbow joints are kept in the unnatural position, are likelier to have the abnormal condition in the soft tissues and the bones forming the elbow joint. This may be given as the reason for the great limit of movements in 'Continental grip' users, in comparison with those who use other kind of 'grip'. The limit of movement of supination, which is rather frequently found, is mostly caused by the abnormal development or changes of position (lateral dislocation) of the head of the radius at the proximal end, and also the abnormal development of the radio-ulnar joints at the proximal end.

The limit of the movement of flexion chiefly results from the abnormal development of the tip of the coronoid prosess, but it is not a rare case that it is due to the abnormal development of the biceps, the triceps, and other soft tissues. 
The limit of the motion of extension is due to the abnormal development of the tip of the olecranon process, the tension the flexors (chiefly biceps)' and the abnormal 'development of other soft tissues. Since the abnormal development of the tip of the olecranon is more remarkable than in the tip of the coronoid process, and also the ab:ıormal developmeat is manifest in the soft tissues, it is clear that the movement of extension is also limited next to the movement of supiuatio:, which is the most limited movement of the elbow joint on the side of the serviceable arm in tennis players.

The limit of the movement of flexion and extension is increased by the hypertrophy of the breadth of the hưmerus.

The abnormal development of the olecranon and the coronoid processes, and the changes of the soft tissues at the elbow joint are mostly caused by the sports like $f$ ncing, javelin-throwing, baseball, etc. in which the upper limb must be used with the greatest momentum in a moment. These symptoms are produced by the burden imposed upon the elbow joiut.

Let us observe the movements of a 'forehand stro'se' based on the 'Eastern grip.'. First, the upper limb of the serviceable arm is drawn backward flexing it slightly in its natural position, while the lower limb on the side of the other arm is stepped forward with the centre of gravity put on the foot at the back. The forearm is kept in the supine position and the carpal joints it the position of dorsal flexion. Then, keeping the same pose, the upper limb on the side of the serviceable arm is carried to the front, shifting gradually the centre of gravity from the hisder foot to the front foot. At the same time, by stretching the triceps, the elbow is extended until-the handle of the racket and the upper limb are on a vertical line: Aud, hitting is complefed at athe moment the centre of gravity is entirely shifted to the front foot." By the force of inertia, the up er limb is carried from the front towards the opposite direction quite naturally, while the elbow joint is slightly flexed nearly in front of the body keepiug the forearm in the prone position. Now the carpal joint is drawn near the clavicula on a opposit side, the former coming in the position of foreflexion 'or. radional flexion. Thus, a stroke is completed. At the moment of hitting the ball 'speed', 'control' and 'rotation'; etc. are given to the ball through the influence of the movements' of supination and pronation of the forearm, the dorsal flexion, the radional flexion, or the ulnar flexion of the carpal joints, ard other subtle motion. Up to the motion of hitting a ball, the': Western grip' is much the same with the 'Eastern grip', but the following differences can be observed. The forearm is kept in supine position letting the carpal joint flex and the? elbow joint is extended at the very moment of hitting. Then, after turving the forearm into the prone position, the arm moves by the force of inertia. Movements of proration and supiuation in the forearm are characteristic of this 'grip', making it suitable' for strong hittirg', because, as stated above, it gives the ball 'drive' by hitting it with the slight flexion' 
of the carpal joint. The fact that 'Western grip' users are smaller both in height and weight than the users of other kind of 'grips', may explain why this 'grip' is fit to those who are smaller in stature.

In view of the characteristics of this 'grip', it seems natural that 'Coutinental grip' users have considerable changes in the elbow joint. But the fact is that our "Continental grip' users use the one into which the 'Eastern grip' is introluced to some extent. The player who uses the genuine 'Continental grip' is seldom found in our country. This seems to show that the burden imposed upon the elbow joint and the carpal joints is too much for our players. Also, this is probably one of the reasons why we have few players with the so-called ' tennis elbow'.

The opinion varies regarding this 'tenuis elbow'; some consider it as the periostitis of the distal end of the upper limb due to its over exertion, and others as radiohumeral bursitis, epicondylitis, and epicondylalgia due to its over exertion. The pathology of 'tennis elbow' probably varies in different cases. In Osgood's personal case there was a small bursa between the tendous of the extensor muscles and the tip of the condyle. It is probable that in other cases there may be localized perinstitis or tears of the muscle origins. Fortunately, no 'tennis elbow' was found in the examined, but there found a certain tennis player aged. 32, who had experienced some trouble in his elbow joint. He forced himself to use a too heavy racket and, what is more, changed his 'grip' from the 'Eastern grip' to the 'Continental grip'. Consequently, about half a month later, he suffured from the slizht swelling and some acute pain in his elbow joint, and was obliged to stop playing tennis for about 8 months. Though it is not sure wether this is really what we call. 'tennis elbow' case or not, judging from its symptoms, I may be right to consider it as the myositis due to its over-exertion. Auother example is fould in Mr. T. Abe, our champion in Davis Cup matches. It is said - that at a certaiu tournament he was forced to exert the movement of backhaud stroke in succession. On the very day towards the evening, he had the swelling and pain in biseps brachialis and was impossible to play tennis for about a month after the medical treatment. This may be regarded as the myositis (biceps brachialis) due to the over-exertion, but not the so-called 'teunis elbow'.

The changes caused by playing tennis are the thickning of the compact.of the bones forming the elbow joint on the side of the serviceable arm, especially the humerus, the ulna and the radius, the narrowness of the spongiosa, the bypertrophy of the medial epicondyle of the humerus, the hypertrophy and the lateral dislocation of the breadth of the head of the radius at the proximal end, and the development of the radio-ulnar joints at the proximal end. Th se are not to be considered as "Sportschaden", but as the result that the elbow $\mathrm{j}$.int has adapted itself to playing tennis. Dr. W. Knoll maintains that the ab- 
uormalities of the elbow joint which are produced in the attachment of the muscles and the tendons are the changes caused by repeating the strong stretching of muscles and tendons in playing tennis and regards it as natural physical changes.

The above-mentioned changes noticed in the bones forming the elbow joint of tennis players are not at all marked, compared with other athletes like fencers, javelin-throwers, baseball players, etc. In the case of tennis players there is little or no kalk production of the capsula articularis, the formation of the fragment, and the abnormal development of the tips of the olecranon and the coronoid, which are often found in other athletes. These are the symptoms due to burden imposed upon the elbow joint which varies according to the kind of sports. Tennis imposes less burden upon the elbow joint than other sports, such as baseball, javelinthrowing, and fencing, etc. And what is common to tennis players and other athletes is that the degrees of the changes in the bones forming the elbow joint and the soft tissues have nothing to do with the age starting the sport and its duration, but with the individual constitution.

On measuring the above-mentioned $x$-ray photograph, if the larger result is got in the serviceable arm than the other, the question is raised whether it is a real one or it is the difference produced by the different le:yth of the soft between the bones and the plate on account of the thickening tissues. To eliminate this difference $5 \mathrm{c.m}$. wire was used.

\section{v. Conclusion.}

(1) The examination was made on our leading male tennis players to observ the changes in their physiques and upper limbs.

(2) a.) Taken as a whole, tennis players physiques were comparatively delicate. b.) Aud most

'Western grip' users were smaller in size. c.) The grasping power of bo'h arms was weaker than that of non-athlete males, but they had the greatest difference between right and left arms, in comparison with other athletes and non-athletes.

(3) The changes observed by the clinical examination of the upper limbs were: a.) The abnormal development of its whole length. b.) The development of the forearm at its largest circumference. c.) The greatest difference of the grasping power between right and left arms, as compared with other athletes. d.) The carying angle was larger in the serviceable arm. e.) The movements of flexion and extension of the elbow joint, and the supination and pronation of the forearm were limited to a slight extent. f.) The dificrence of changes had nothing to do with the date starting playing tennis or its duration. g.) but with the kind of 'grip' used.

(4) (A) By the observation of the ventro-dorsal photograph.

a.) The serviceable arm usually well developed. b.) In some cases the medial surface of 
the humerus reaching to the medial epicondyle was bulging and showed an upheaval. In the serviceable arm $22 \%$ was found in this condition, and in the other $11 \%$, which was rather small in percentage, as compared with other athletes. c.) In the part covering from the lateral surface of the medial epicondyle to its lower surface the following four shapes were found:

1. Round-shaper.

2. Square-shaped.

3. Spine-shaped.

4. Trapezoid.

(1. Round-shaped-in the serviceable arm, 13\%, the other, 4\%. 2. Square-shapedin the serviceable arm, $57 \%$, the other, 40\%. 3. Spineshaped - in the serviceable arm, 18\%, the other, 6\%. 4. Trapezoidin both arms, $12 \%$.)

d.) Two cases had some speckles in the lower part of the medial epicondyle. But 3.0 case was found to have the fragments which was occasionally found in other athletes. e.) As for the shape of the lateral surface of the head of the distal end of the humerus, the following six shapes could be found :

1. Square-shaped. 2. Round-shaped.

3. Square-round-shapəd. 4. Round-square-shaped. 5. Wave-shaped. 6. Sirineshaped.

(1. Square-shaped - in the serviceable arm, $11 \%$, the other, $2 \%$

2. Round-shaped - " " " $3 \%,, \quad, 63 \%$

3. Square-round-shaped - " " , , $50 \%, \quad$ " $20 \%$

4. Round-square-shaped - " " "13\%, " , $9 \%$

5. Wave-shaped - in both arms, $6 \%$.

6. Spine-shaped - 17\%, only in the serviceable arm.)

g.) Th process of the trochelea humeri was found bigger in the serviceable arm. h.) The development of the compact of the humerus was remarkable in the serviceable arm. (Eastern grip - 61,3\%, Western grip - 71,4\%, Continental grip -66,6\%.) i.) Some cases; had the undul ating surface of the elbow joint of the humerus at the distal end, which 
was found chiefly in the serviceable arm, but not so much as other athletes, such as fencers, javelin-throwers, baséball players. j.) The coronoid process mostly hypertrophied in the serviceable arm and some cases had the one dislocated laterally or upwards, which was also small in number. $k$.) The olecranon process, and 1.) the head of the radius at the proximal end showed good development in the serviceable arm. m.) No ease had image of the fragment near the upper surfrce of the olccranon process, which was found in fencers, baseball players, and javelin-throwers. n.) The compact of the ulna was remarkable thickened in the serviceable arm.: o.) $24,1 \%$ of the examined temmis players had the narrow spongiosa. p.) The fossa of the head of the radius at the proximal e:t was larger in diameter and mostly shallower a bit. q.) The compact of the radius thickened, though not so much as that of the humerus and the ulna. r.) The tuberosity of the radius generally develops better on the side of the serviceable arm than the other and usually in the serviceable arm the upper surface formed the steeper angle of inclination against the longitudinal axis of the radius than the other arm. This was found in $47 \% \therefore$ (Eastern grip $-31,9 \%$, Western grip- $57,1 \%$, Contineutal grip - 66,6\%.)

(B) By the obsurwion of the lateral photograph.

a.) In each of four cases (74\%) there was one spine-shaped process (an excess bone) formed near the distal eud of the posterior surface of the humerus. $\dot{b}$.) As a whole, the olecranon was well developed. c.) In some cases the olecranon process was extended upwards or inwards. d.) In baseball players and javelin-throwers there were three cases whose olecranon process was fractured on its tip. But this was not found in teninis players. e.) The following three shapes were found in the upper surface of the olecranon process:
1. Round-shaped.
2. Square-shaped.
3. Spine-shaped.

(1. Round-shaped. . . 74 cases. (the serviceable arm . . . 33)

2. Square-shaped . . $30, \quad(, \quad, \cdots, " . .17)$

3. Spine-shaped . . 4 , (all in the serviceable arm)

f.) On the whole, the coronoid process was good in development. And especially four cases (7.4\%) were so good that it seems to cause the limit of movement of flexion. (Eastern grip - one case, Western grip - tow cases, Continental grip - one case.)

These observation are in accord with clinical observations.

\section{The explanatory notes about the figures.}

Fig. 1. A lateral $x$-ray picture of a tennis player. (The serviceable arm.)

2. " " " " " (The other arm.)

3. A V-D x-ray picture of him. (The serviceable arm.) 
4. A V-D x-ray picture of him. (The other arm.)

5. A V-D x-ray picture of a swimmer. (The serviceable arm.)

6. $\quad, \quad, \quad, \quad$ (The other arm.)

7. A lateral x-ray picture of a fencer. (The serviceable arm.)

8. " , " " " " (The other arm.)

9. A V-D x-ray picfure of a javelin-thrower. (Mr. Sumiyoshi.) (The serviceable arm.)

10. His other arm.

11. A lateral $\mathrm{x}$-ray picture of a javelin-thrower. (Mr. Kunii.) (The serviceable arm.)

12. A V-D x-ray picture of him. (The serviceable arm.)

13. A V-D $\mathrm{x}$-ray picture of a baseball player. (Mr. Kajiwara.) (The serviceable arm.)

14. His other arm.

15. A lateral x-ray picture of a baseball player. (Mr. Hatanaka.) (The serviceable arm.)

16. " " " " " " (The other arm.)

17. A V-D x-ray picture of him. (The serviceable arm.)

18. $" \quad, \quad " \quad$ (The other arm.)

19. A lateral $x$-ray pieture of a non-athlete male. (The serviceable arm.)

20.
,
$", \quad$,
„ (The other arm.)

21. A V-D x-ray picture of him. (The serviceable arm.)

22

23. A lateral $x$-ray picture of a non-athlete female. (The serviceable arm.)

24.
,
" , . ,
, (The other arm.)

,

25. A V-D x-ray picture of her. (The serviceable arm.)

26.
"
"
"
(The other arm.) 
Fig. 1

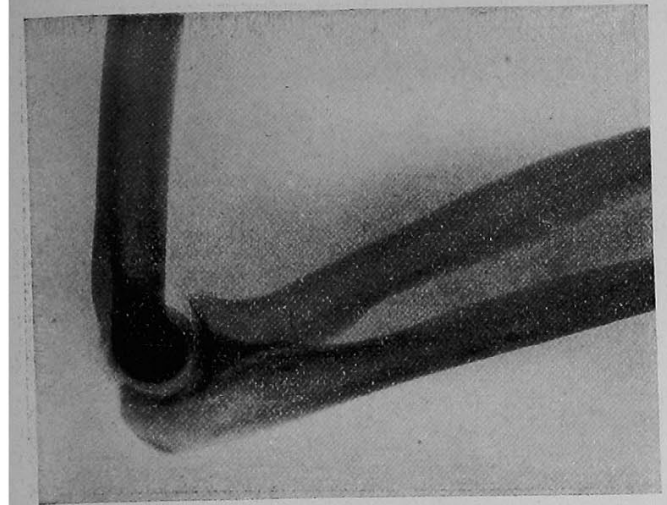

Fig. 3 .

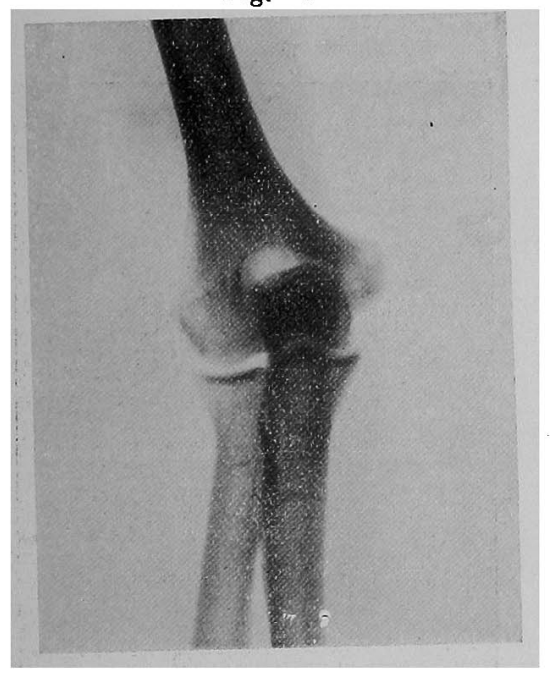

Fig. 5.

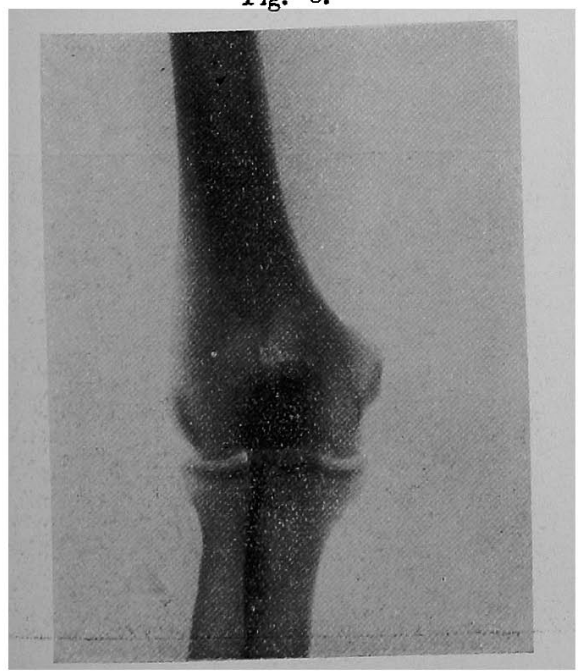

Fig. 2.

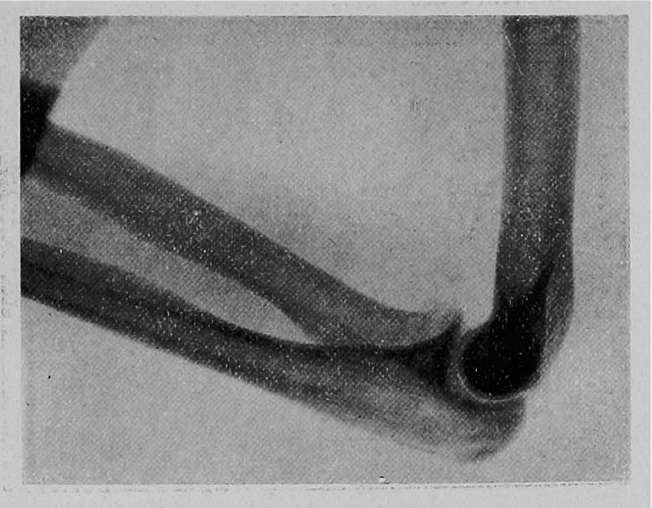

Fig. 4.

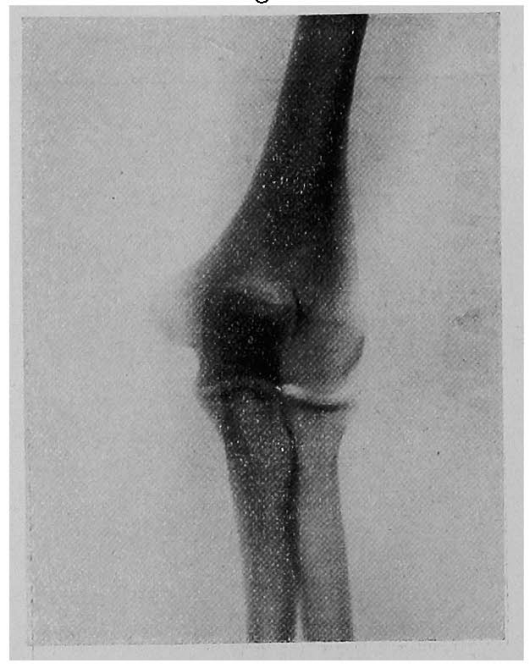

Fig. 6.

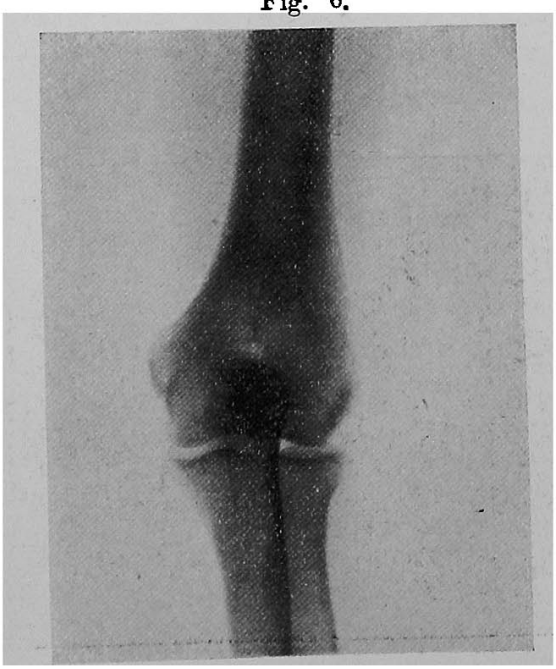


Fig. 7.

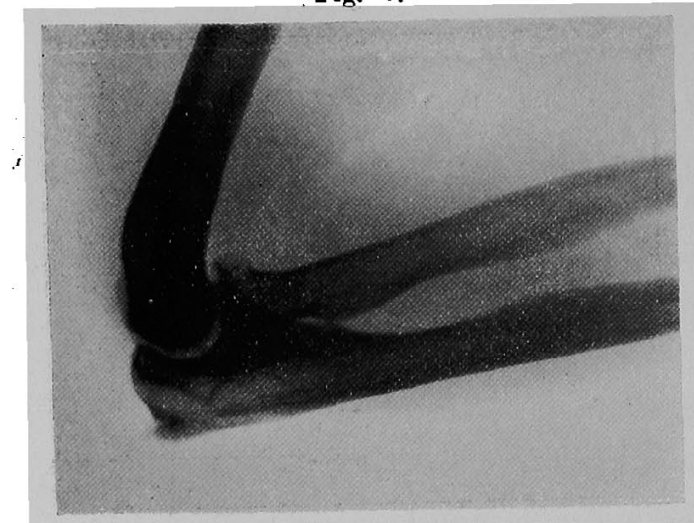

Fig. 9.

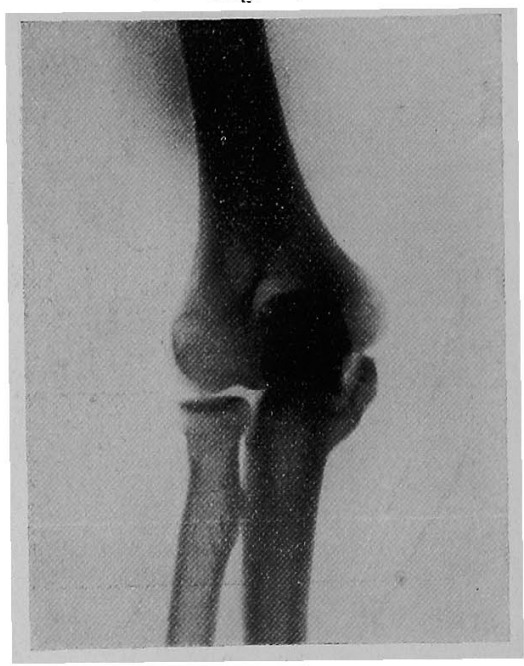

Fir. 11

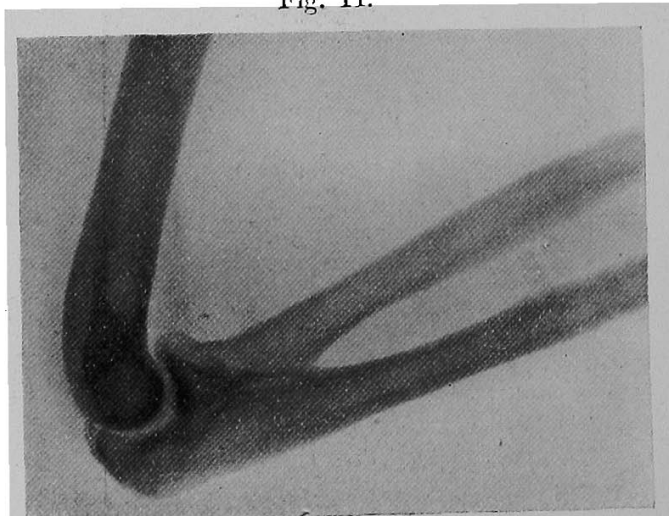

Fig. 8.

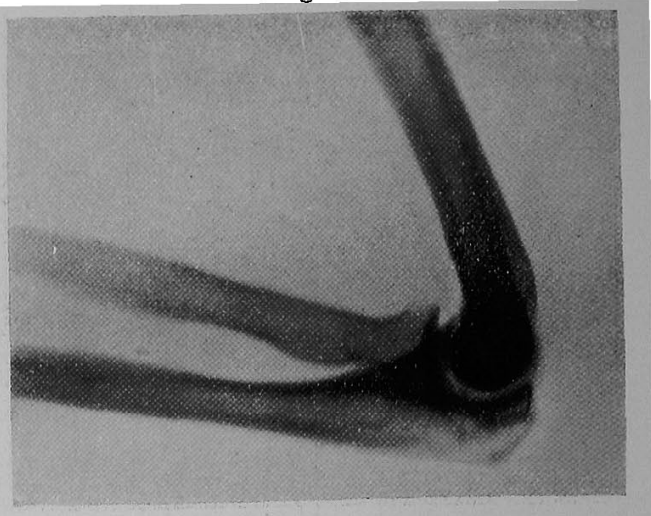

Fig. 10.

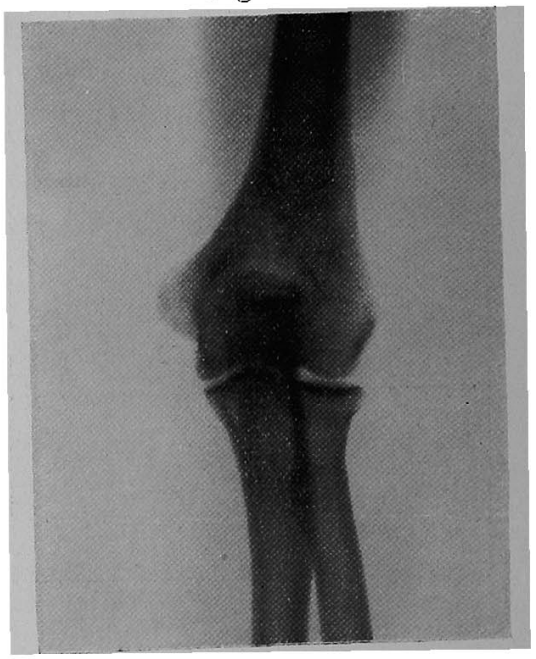

Fig. 12.

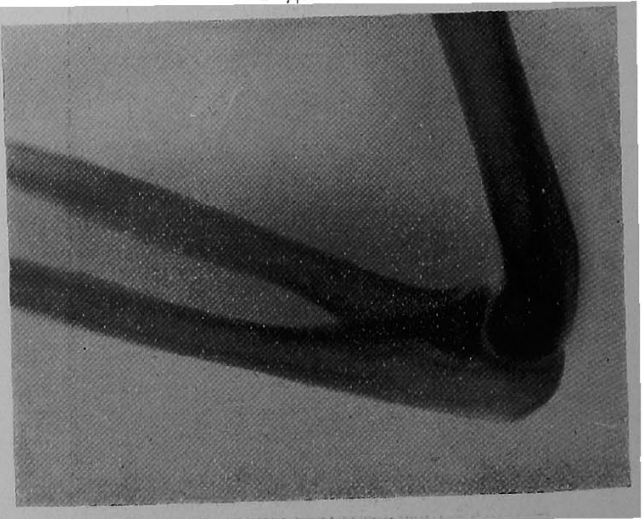


Fig. 13.

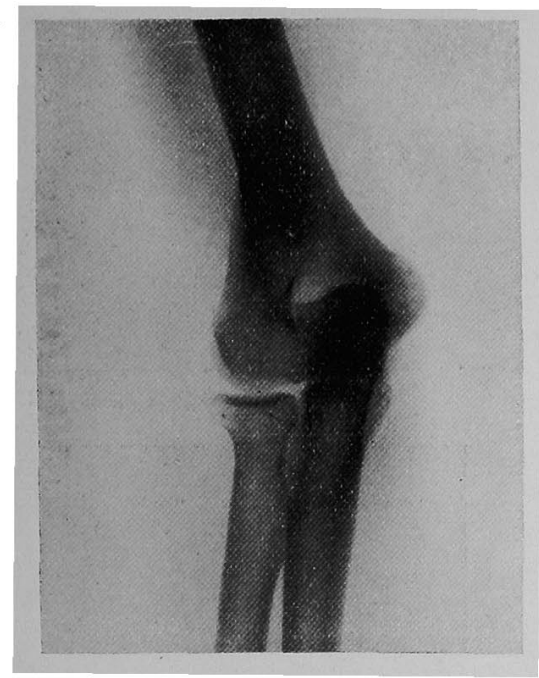

Fig. 15.

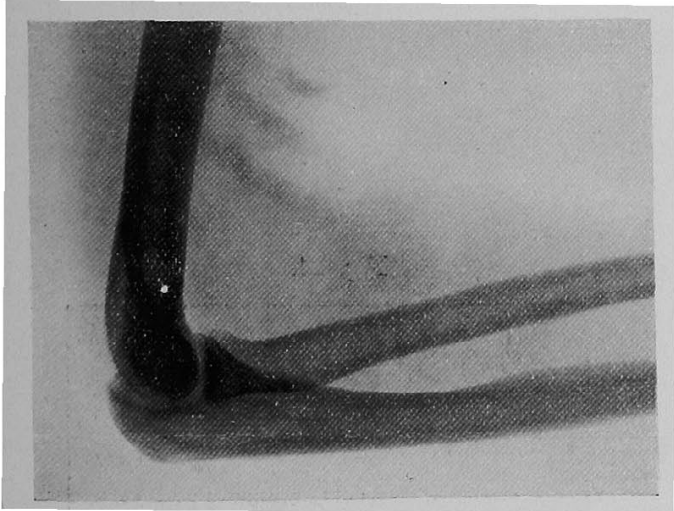

Fig. 17 .

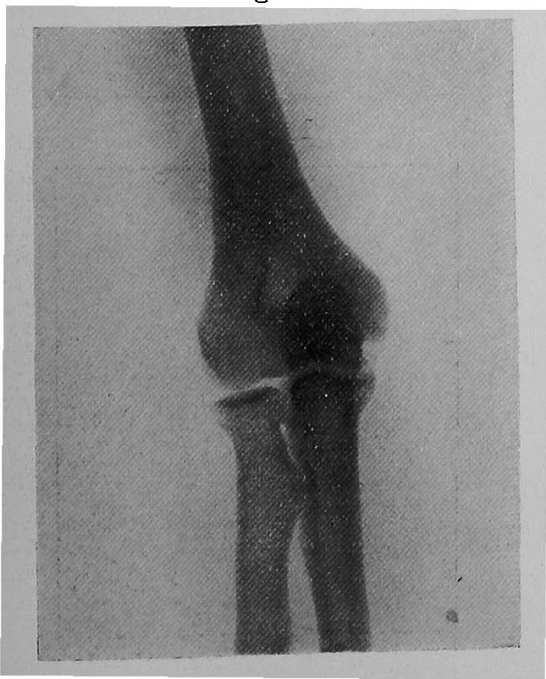

Fig. 14.

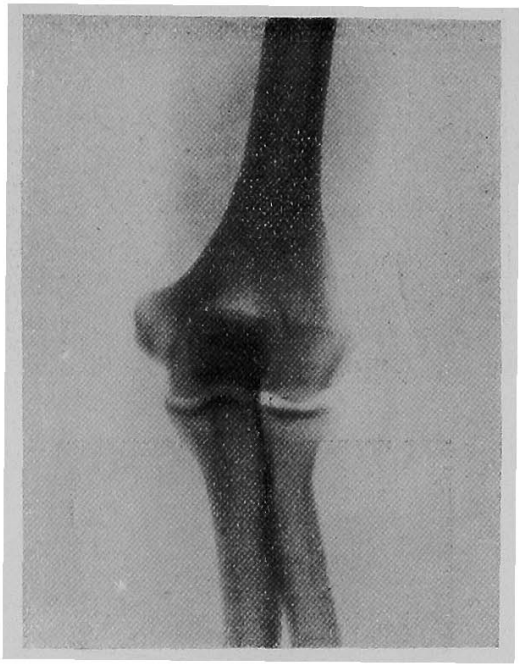

Fig. 16.

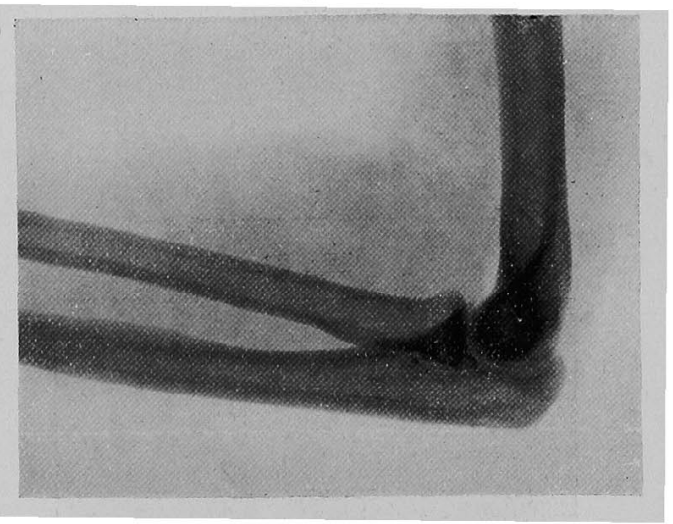

Fig. 18.

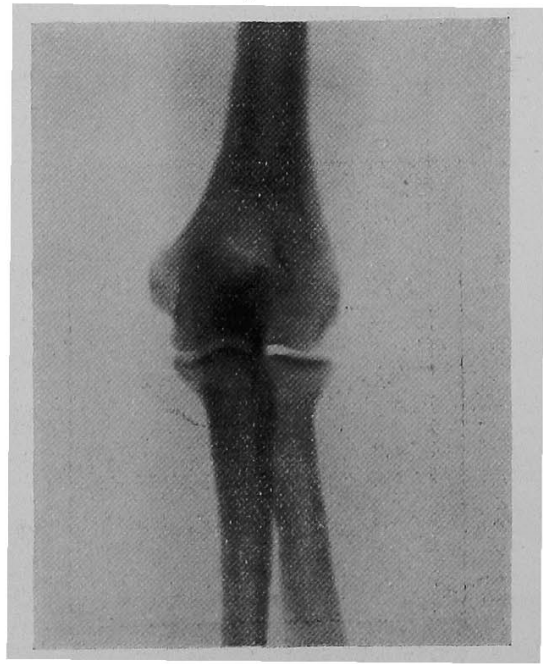


Fig. 19.

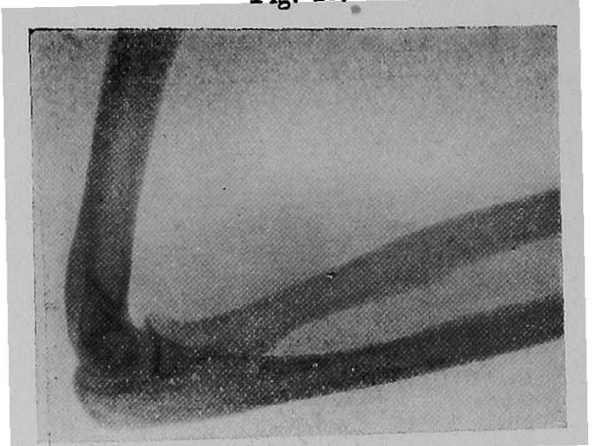

Fig. 21.

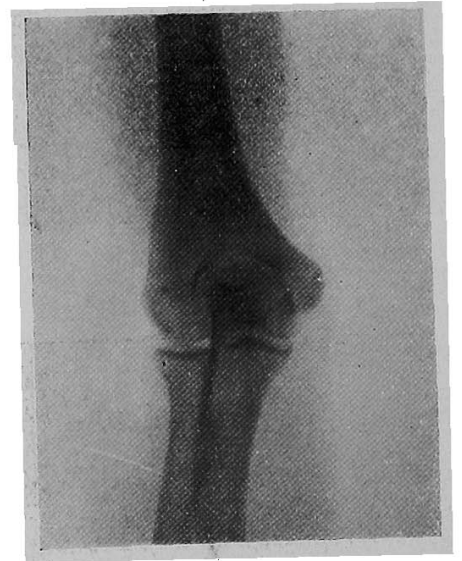

Fig. 23.

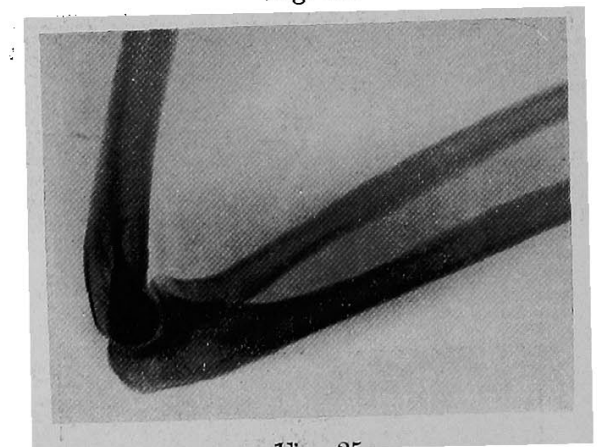

Fijg. 85.

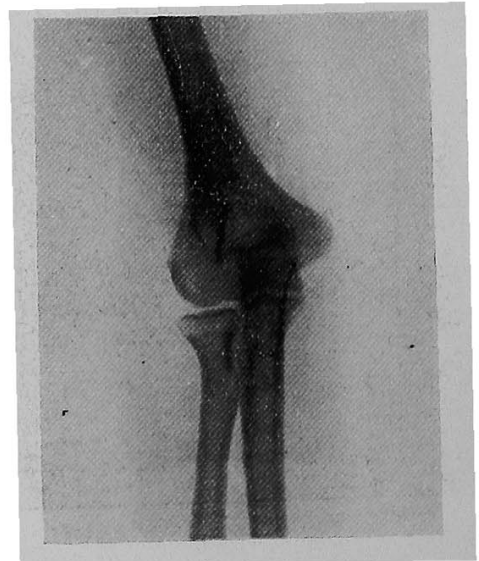

Fig. 20.

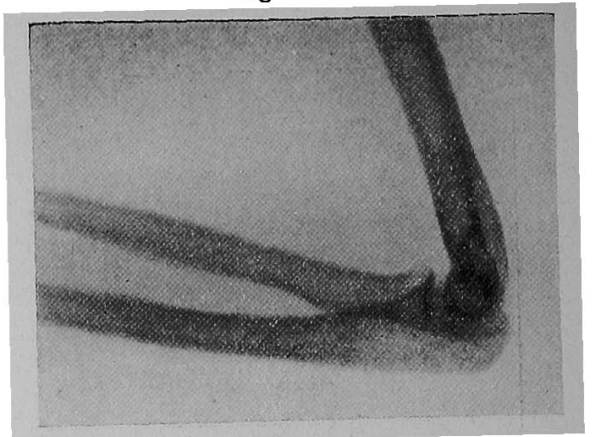

. Fig. 92.

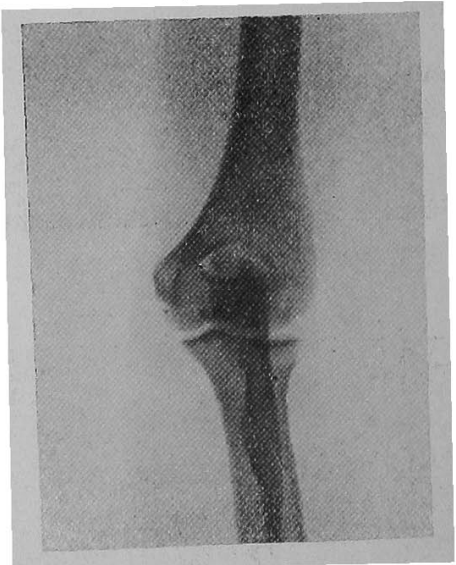

Fig. 24 ,

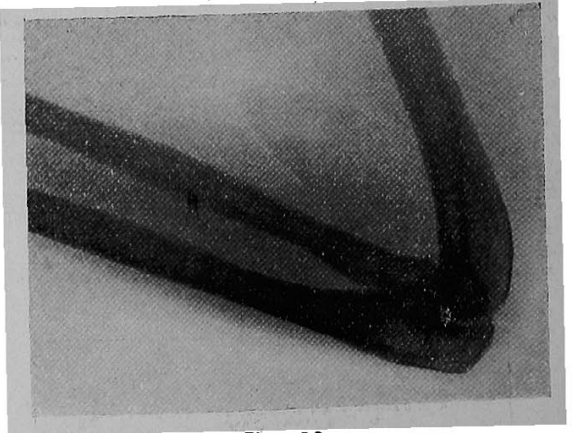

Fig. 26 .

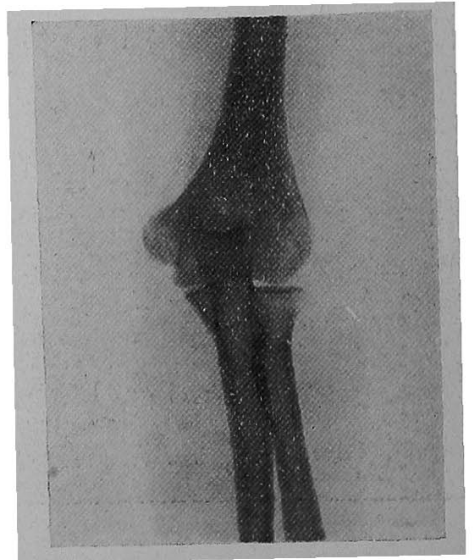

